NASA Technical Memorandum 101523

AVSCOM Technical Memorandum 88-B-016

\title{
AN INITIATIVE IN MULTIDISCIPLINARY OPTIMIZATION OF ROTORCRAFT
}

Howard M. Adelman and Wayne R. Mantay

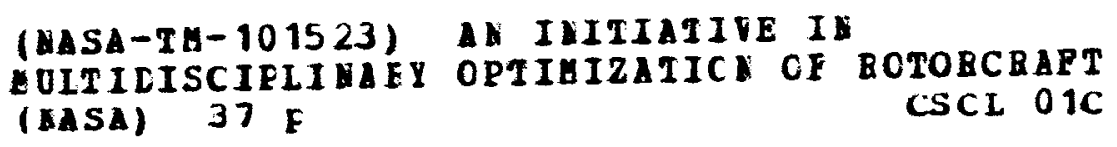

\author{
N $89-15108$ \\ $\begin{array}{ll}\text { Unclas } \\ \text { G3/05 } & 0185220\end{array}$
}

\section{October 1988}
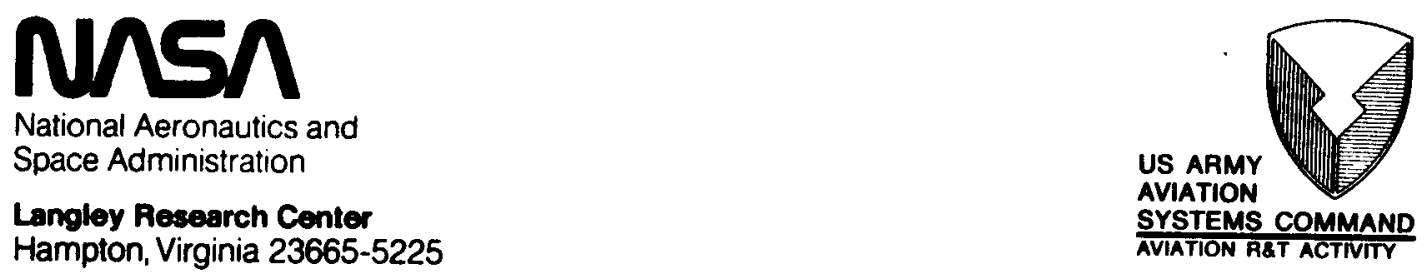


\section{INTRODUCTION}

An emerging trend in the analytical design of aircraft is the integration of all appropriate disciplines in the design process (refs. 1,2). This means not only including limitations on the behavior of the design from the various disciplines, but also defining and accounting for interactions so that the disciplines influence design decisions simultaneously rather than sequentially. The integrated approach has the potential to produce a better product as well as a better, more systematic design practice. In rotorcraft design (the rotor in particular), the appropriate disciplines include aerodynamics, dynamics, structures, and acoustics. The purpose of this paper is to describe a plan for developing a helicopter rotor design optimization procedure which includes the above disciplines in an integrated manner.

Rotorcraft design is an ideal application for integrated multidisciplinary optimization. There are strong interactions among the four disciplines cited previously; indeed, certain design parameters influence all four disciplines. For example, rotor blade tip speed influences dynamics through the inertial and air loadings, structures by the centrifugal loadings, acoustics by local Mach number and air loadings, and aerodynamics through dynamic pressure and Mach number. All of these considerations are accounted for in current design practice. However, the process is sequential, not simultaneous, and often involves correcting a design late in the design schedule.

Applications of rigorous and systematic analytical design procedures to rotorcraft have been increasing, especially in the past five years. Procedures have accounted for dynamics (refs.3-9), aerodynamics (refs. 10-11), and structures (ref. 12). Generally, these applications have only considered single-discipline requirements, although in reference 5, dynamic and structural requirements were considered together, and in reference 6 , dynamics and aeroelastic stability were combined. Integrated multidisciplinary applications to rotorcraft are largely nonexistent.

In early 1985, several occurrences led to an excellent opportunity at the NASA Langley Research Center to address the multidisciplinary design problem for rotorcraft. The Interdisciplinary Research Office was established and charged with the development of integrated multidisciplinary optimization methods. Nearly concurrently, the Army Aerostructures Directorate at Langley established the goal of improving rotorcraft design methodology by "discipline integration." Close cooperation between the NASA and Army organizations led to initial plans for a comprehensive, integrated analytical design capability. By 1986, a group of NASA/Army researchers had formed a committee and began detailed planning for this activity. The committee, designated IRASC (Integrated Rotorcraft Analysis Steering Committee), has now completed the bulk of the planning and has formulated the approach described in this paper. 
The development of an integrated multidisciplinary design methodology for rotorcraft is a threephased approach. In Phase 1, the disciplines of blade dynamics, blade aerodynamics, and blade structures will be closely coupled, while acoustics and airframe dynamics will be decoupled from the first three and will be accounted for by effective constraints on the other disciplines. In Phase 2 , acoustics will be integrated with the first three disciplines. Finally, in Phase 3, airframe dynamics will be fully integrated with the other four disciplines. This paper deals only with the Phase 1 approach and includes: details of the optimization formulation, design variables, constraints, and objective function as well as details of discipline interactions, analysis methods, and methods for validating the procedure. 


\section{LANGLEY PARTICIPANTS IN THE ACTIVITY}

The work described in this paper represents the combined efforts of a team of researchers and managers at the NASA Langley Research Center and Army Aerostructures Directorate involved in analysis and optimization of rotorcraft. Shown on the left side of figure 1 are the members of the IRASC (Integrated Rotorcraft Analysis Steering Committee). Shown on the right side of the figure are the technical contributors. This team includes experts in the areas of rotorcraft aerodynamics, dynamics and aeroelasticity, structures, and acoustics, as well as optimization and sensitivity analysis.

Integrated Rotorcraft Analysis Steering Committee (IRASC)

Wayne Mantay Chairman Howard Adelman Vice-Chairman Ray Kvaternik

Mark Nixon

Paul Pao

Kevin Noonan
Technical Contributors

Aditi Chattopadhyay Ruth Martin T. Sreekanta Murthy Jocelyn Pritchard Joanne Walsh Matt Wilbur

Figure 1 


\section{OBJECTIVE OF THE EFFORT}

Figure 2 represents the Charter of the IRASC activity. The unique features of the work are the emphasis on integrating the disciplines and explicitly accounting for the interactions among disciplines. While the team does not intend to develop new or improved analyses in any of the included disciplines, the latest developments in rotorcraft disciplinary analysis will be used. Finally, it is a goal of the team to stimulate activity in the rotorcraft (and the aircraft) community in the general area of multidisciplinary design integration and the use of formal Mathematical Programming in design work.

\section{Develop and validate an integrated multidisciplinary design capability involving aerodynamics, dynamics, structures, and acoustics which leads to improved design practices and improved rotorcraft.}

Figure 2 


\section{FUNDAMFNTAL DECISION/STRATEGY}

The rotorcraft optimization effort at Langley has a three-phased plan (fig. 3). The initial phase, which is well underway, will decompose the rotor design problem. This will be accomplished by driving the design through the integration of the disciplines of aerodynamics, dynamics, and structures while satisfying additional constraints imposed by airframe dynamics and rotor acoustics. The latter constraints will account for the influences of the airframe response and acoustics behavior on the overall optimization process. Phase 2 of the design plan will include rotor acoustics as a discipline inside the optimization loop; that is, integrated with aerodynamics, structures, and dynamics. Finally, in Phase 3 of the effort, all five disciplines will be fully integrated inside of an iterative design loop. This paper focuses primarily on the Phase 1 activity.

\section{Phase 1}

- Decompose the design problem

- Blade aerodynamics, dynamics, structures

- Airframe analysis/modeling and acoustics

- Develop representation of acoustics and airframe influences on blade aerodynamic, dynamic, structural optimization

Phase 2

- Bring acoustics into optimization loop

Phase 3

- Bring airframe dynamics into optimization loop

Figure 3 
FOCUS NO. 1 - WHITE PAPER

Publication and critique of a "white paper" (fig. 4) detailing the plan for rotorcraft optimization at Langley is viewed as a prime focal point of the activity. The paper, which is presently in draft form, will present the goals of the design effort, as well as the approach and validation plan. The approach will discuss strategy, analytical methods, and discipline couplings. The validation procedure will document test problems to be used to examine the fidelity of the specific discipline tools used, as well as the overall optimization procedure. Finally, the white paper will be disseminated to industry for critique and a workshop is planned to consolidate feedback to the plan.

- Goals of the activity

- Approach and plan

- Formulation of optimization strategy

- Governing mathematics (varying detail)

- Definition of interactions

- Analysis methods (codes) to be used

- Validation methods - test problems

- Status

- First draft written

- To be critiqued by industry

Figure 4 
FOCUS NO. 2 - ROTOR DESIGN

A practical rotor design will be the end result of the Langley optimization effort (fig. 5). The purpose of this "fidelity check" includes not only an overall test of the methodology, but also a measure of each discipline's modeling effectiveness. The test problem for Phase 1 will contain a rotor task, mission scenario, and challenging design requirements. Simulation models describing aerodynamic, structural, and dynamic systems will be formulated to allow for key interdisciplinary couplings. Design variables, constraints, and a specific objective function will be identified. As the design activity progresses, so will the verification of individual discipline models. Finally, the optimum design will be wind-tunnel tested for fidelity of the entire Phase 1 process.

- Apply Phase 1 method to rotor design

- Define test problem

- Rotor task and mission

- Design requirements

- Generate math models

- Aerodynamic

- Dynamic

- Structure

- Incorporate couplings

- Formulate optimization problem

- Objective function

- Design variables

- Constraints

Validate design methodology

- Discipline tools

- Overall

Figure 5 


\section{INTEGRATED ROTORCRAFT OPTIMIZATION DEVELOPMENT PLAN}

Figure 6 depicts the general sequence of tasks that will lead to a fully integrated rotor blade aerodynamic/dynamic/structural optimization procedure which also accounts for acoustic and airframe dynamic influences. The dynamic optimization work is building on the work described in references 5,6 , and 9 . The rotor aerodynamics activity has been separated into two parts. The first is aerodynamic performance optimization which is a continuation of the work described in reference 10. The second is an integration of aerodynamic loads analysis with dynamics - a procedure wherein the local airloads can be adjusted by varying the planform dimensions and twist of the blade to reduce dynamic response. A merger of the rotor performance optimization with the airload/dynamics optimization will yield a fully integrated aerodynamic/dynamic procedure. The rotor structural optimization is a continuation of the work of reference 12. A merger of all the aforementioned procedures, with the acoustic and airframe constraint interfaces, will lead to the fully integrated Phase 1 procedure. The resulting capability will be applied to a rotor test article to validate the procedures.

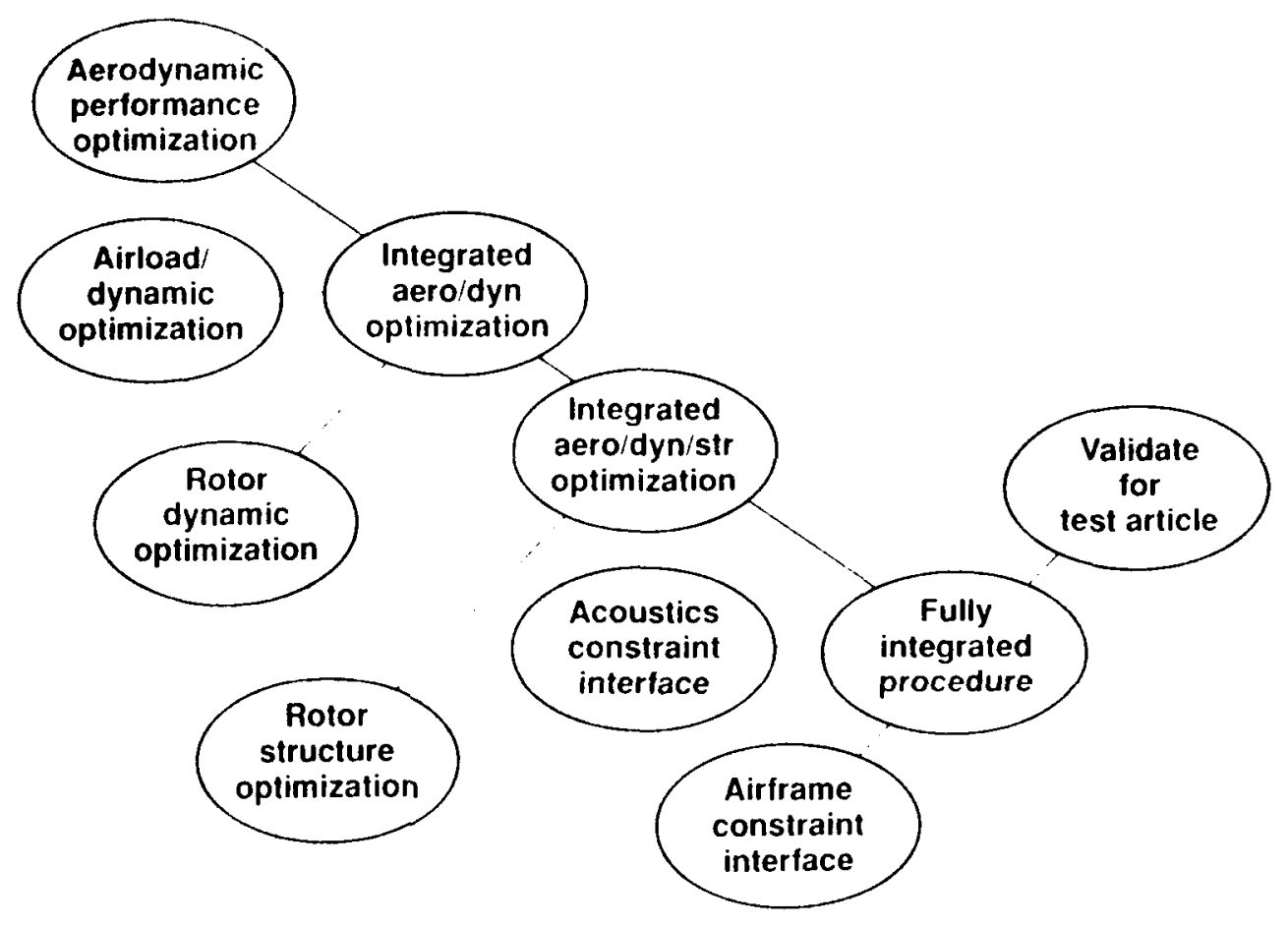

Figure 6 


\section{DEFINITION OF THE OPTIMIZATION PROBLEM}

As indicated in figure 7, the next section of the paper consists of details of the integrated rotorcraft optimization problem. Included are descriptions of the following: the objective function (the quantity to be minimized for obtaining an optimum design); the design variables (dimensions and other parameters of the design); constraints (a set of behavioral or characteristic limitations required to assure acceptable and safe performance); and definitions of the interactions among the disciplines.

- Objective function

- Design variables

- Constraints

- Interactions among disciplines

Figure 7 


\section{CONTRIBUTORS TO OBJECTIVE FUNCTION}

In formulating the objective function, a number of indicators (fig. 8) were considered. Basically, the indicators fell into two categories - penalty types such as weight and cost; and performance types such as vibratory loads (shears and moments); and required horsepower. It was decided, for the purpose of the Phase 1 work, to choose performance type quantities for the objective function; specifically, transmitted vertical vibratory hub shear and horsepower required at several flight conditions. Blade mass will be prevented from becoming excessive by enforcing an upper limit constraint. Cost is not explicitly accounted for in the formulation.

\section{- Blade mass}

- Cost

- Vibratory loads

- Required horsepower

Figure 8 


\section{FORM OF OBJECTIVE FUNCTION}

The objective function is a linear combination of the main rotor horsepower at five flight conditions plus the transmitted vertical vibratory hub shear at a frequency of $\mathrm{N}$ times the blade angular speed (where $N$ is the number of blades). As shown in figure 9, the objective function contains weighting factors $\mathrm{K}_{1}$ through $\mathrm{K}_{6}$ which will be assigned based on a mission criterion to be determined. The five flight conditions referred to above include hover, cruise, high speed, maneuver, and maximum range. The speed and load factor specifications for these conditions are given in the lower portion of the figure.

- Linear combination of main rotor horsepower at five flight conditions and transmitted vertical hub shear

- $F=\mathrm{K}_{1} \mathrm{HP}_{1}+\mathrm{K}_{2} \mathrm{HP}_{2}+\mathrm{K}_{3} \mathrm{HP}_{3}+\mathrm{K}_{4} \mathrm{HP}_{4}+\mathrm{K}_{5} \mathrm{HP}_{5}+\mathrm{K}_{6} \mathrm{~S}$

\begin{tabular}{|c|l|c|c|}
\hline $\begin{array}{c}\text { Flight } \\
\text { condition }\end{array}$ & Description & $\begin{array}{c}\text { Velocity } \\
\text { (Kts) }\end{array}$ & $\begin{array}{c}\text { Load } \\
\text { Factor }\end{array}$ \\
\hline 1 & Hover & 0 & 1.0 \\
2 & Cruise & 140 & 1.0 \\
3 & High Speed & 200 & 1.0 \\
4 & Maneuver & 120 & 3.5 \\
5 & Max. Range & 95 & 1.0 \\
\hline
\end{tabular}

Figure 9 


\section{BLADE MODEL AND DESIGN VARIABLES}

Figure 10 is a depiction of the rotor blade model to be used in the Phase 1 optimization activity. Also shown in figure 10 are the design variables which are defined in figure 11. The blade model can be tapered in both chord and depth. The depth can be linearly tapered from root to tip. The chord is constant from the root to a spanwise location (referred to as the point of taper initiation) and is linearly tapered thereafter to the tip. Design variables which characterize the overall shape of the blade include the blade radius, point of taper initiation, taper ratios for chord and depth, the root chord, the blade depth at the root, the flap hinge offset, and the blade maximum twist. Tuning masses located along the blade span are characterized by the magnitude and locations. Design variables which characterize the spar box beam cross-section include the wall thicknesses at each spanwise segment and the ply thicknesses at $0^{\circ}$ and $\pm 45^{\circ}$ Additional design variables include the number of rotor blades, the rotor angular speed, and the distribution of airfoils.
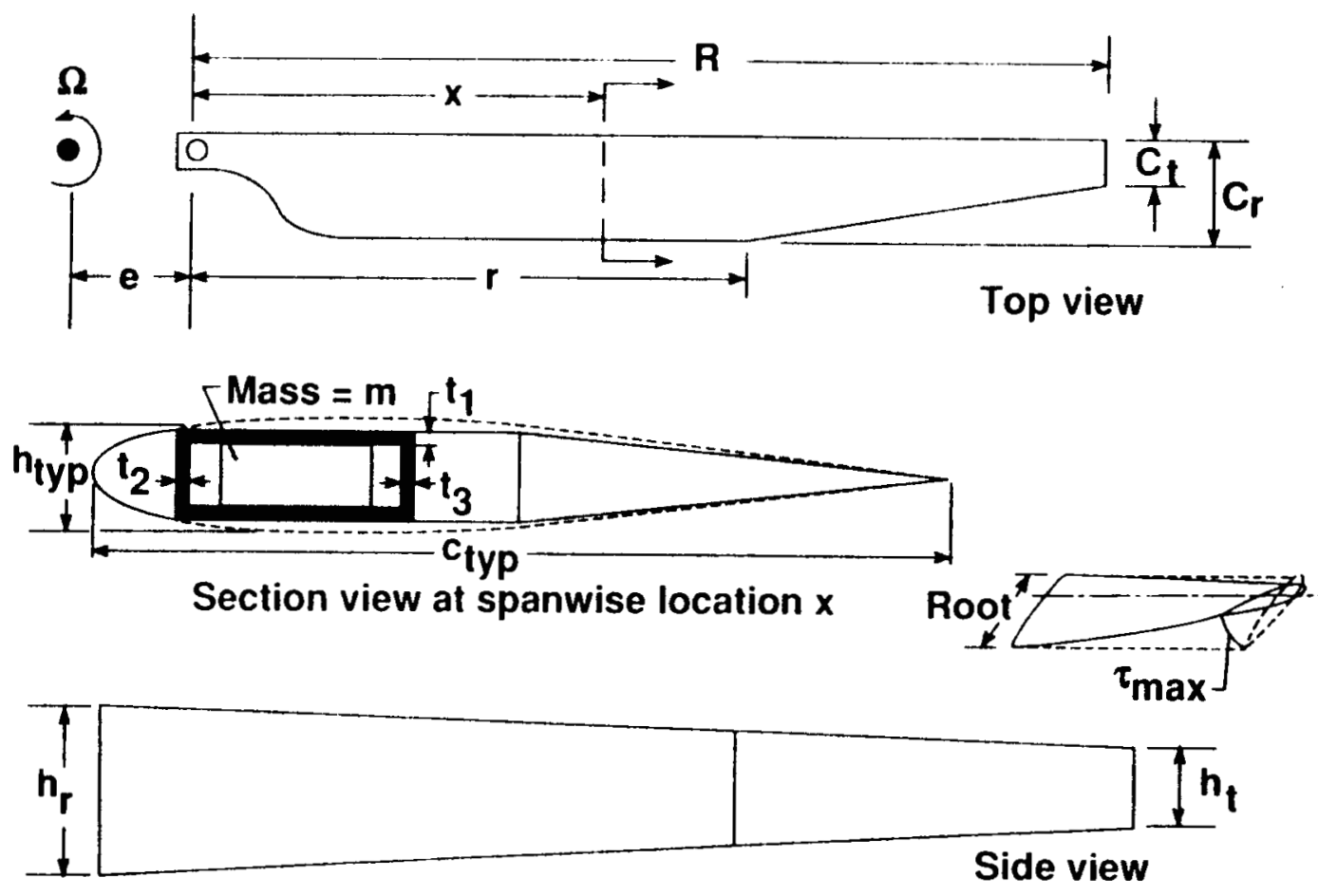

Figure 10 


\section{SUMMARY OF DESIGN VARIABLES}

\begin{tabular}{|l|c|}
\hline \multicolumn{1}{|c|}{ Description } & Symbol \\
\hline Tuning mass at location $i$ & $M_{i}$ \\
Spanwise location of $i-t h$ mass & $X_{i}$ \\
Wing box dimensions & $t_{1}, t_{2}, t_{3}$ \\
Ply thicknesses & $t_{45}, t_{0}$ \\
Depth of blade at root & $h_{r}$ \\
Ratio of blade depths at tip and root & $\lambda_{h}=h_{r} / h_{t}$ \\
Maximum pre-twist of blade & $\tau \max$ \\
Percent blade span where taper begins & $r$ \\
Width of blade at root & $C_{r}$ \\
Airfoil distribution & - \\
Hinge offset & $e$ \\
Blade angular velocity & $\Omega$ \\
Number of blades on rotor & $N$ \\
Blade radius & $R$ \\
Ratio of root chord to tip chord & $\lambda_{c}=C_{r} / C_{t}$ \\
\hline
\end{tabular}

Figure 11 


\section{CONSTRAINTS OVERVIEW}

As previously described, the Phase 1 activity is based on integrating the blade aerodynamic, dynamic, and structural analyses within the optimization procedure. The acoustics and airframe dynamics analyses are decoupled from the first three disciplines and their influences are expressed in terms of constraints. Accordingly, the total set of constraints is made up of two subsets as indicated in figure 12 . The first subset consists of constraints which are evaluated directly from the first three disciplinary analyses and are a direct measure of the degree of acceptability of the aerodynamic, dynamic, and structural behavior. The second subset represents indirect measures of the satisfaction of constraints on the acoustics behavior and the requirement of avoiding excessive vibratory excitation of the airframe by the rotor.

- Aerodynamic

- Dynamic

- Structure

- Acoustic

- Airframe

\section{Evaluated directly} from analysis

\author{
Expressed indirectly \\ as constraints on \\ disciplines in top group
}

Figure 12 


\section{SUMMARY OF CONSTRAINTS}

The constraints are summarized in figures 13 and 14. The first two constraints are for aerodynamic performance and require that for all flight conditions, main rotor horsepower not exceed available horsepower and that airfoil section stall not occur at any azimuthal location. The next nine constraints address blade dynamics. The first requires that the blade natural frequencies be bounded to avoid approaching any multiples of rotor speed. The next five impose upper limits on the blade vertical and inplane loads, transmitted hub shear, and hub pitching and rolling moments. The next three dynamic constraints are an upper limit on blade response amplitude, a lower limit on blade autorotational inertia, and finally, the aeroelastic stability requirement. The structural constraints consist of upper limits on box beam stresses, blade static deflection, and blade twist deformation. The acoustic constraints are expressed as an upper bound on the tip Mach number and tip thickness to limit thickness noise; and an upper bound on the gradient of the lift distribution to limit blade vortex interaction (BVI) and loading noise. The effective airframe constraints are expressed first as a separation of the fundamental blade inplane natural frequency in the fixed system from the fundamental pitching and rolling frequency of the fuselage. Second is a bounding of the blade passage frequency to avoid the proximity to any fuselage frequency. The final constraint is an upper limit on the blade mass which will avoid any designs which satisfy the constraints at the expense of large mass increases.

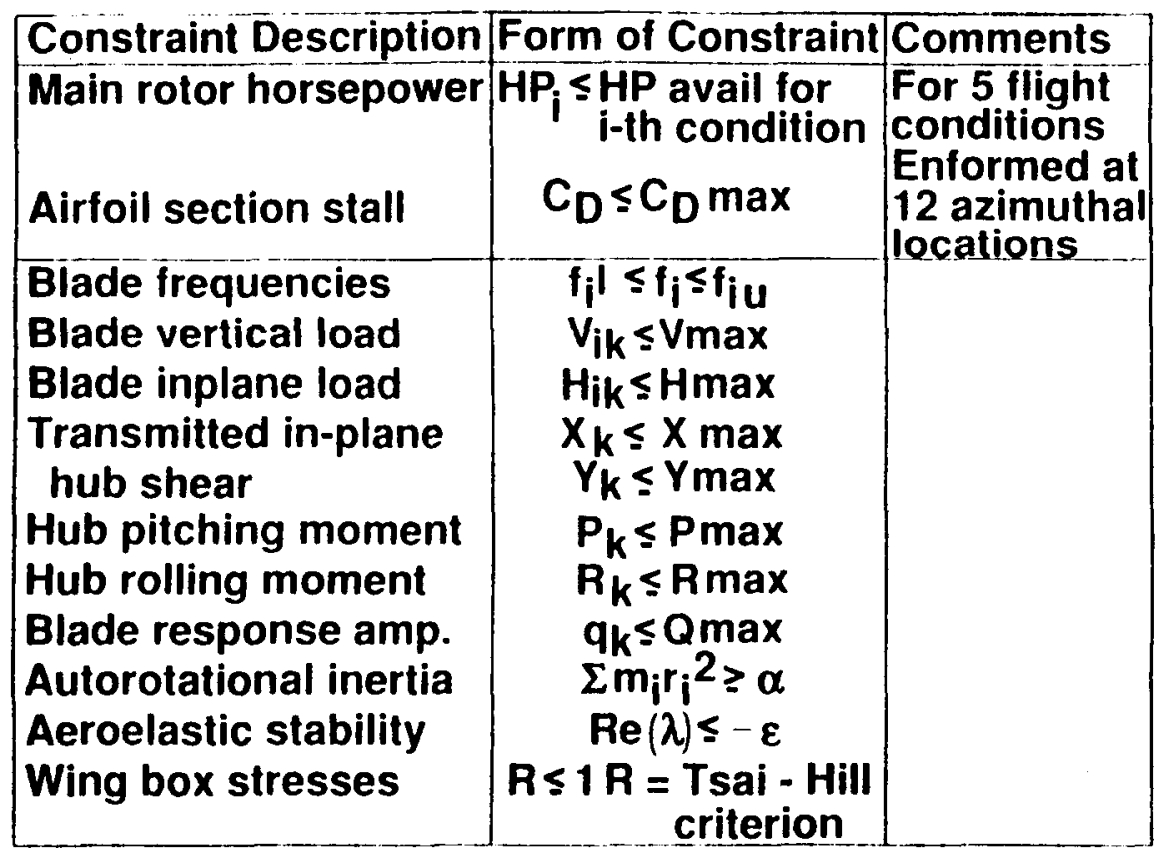

Figure 13 


\begin{tabular}{|c|c|c|}
\hline $\begin{array}{l}\text { Blade tip deflection } \\
\text { Blade twist }\end{array}$ & $\begin{array}{l}W \leq W \max \\
\theta \leq \theta \max \end{array}$ & \\
\hline $\begin{array}{l}\text { Blade tip Mach no. } \\
\text { Blade thickness }\end{array}$ & $\begin{array}{c}M \leq M \max \\
h \leq h \max \end{array}$ & $\begin{array}{c}\text { Limits } \\
\text { thickness } \\
\text { noise }\end{array}$ \\
\hline Blade lift distribution & $d C_{1} / d x \leq S \max$ & $\begin{array}{c}\text { Limits BVI } \\
\text { \& loading } \\
\text { noise }\end{array}$ \\
\hline $\begin{array}{l}\text { Ground resonance } \\
\text { Rotor/Airframe } \\
\text { frequency coupling }\end{array}$ & $\begin{array}{c}\left|\Omega-W_{11}\right| \leq W_{a f} \\
f_{1} \leq N \Omega \leq f_{u}\end{array}$ & $\begin{array}{c}\text { Effective } \\
\text { airframe } \\
\text { constraint }\end{array}$ \\
\hline Blade mass & $M \leq M$ upper & \\
\hline
\end{tabular}

Figure 14 


\section{ANALYSIS ASPECTS}

The analytical tools (summarized in fig. 15) must provide technical fidelity in phenomena prediction, as well as connectivity between disciplines. The areas of aerodynamics, dynamics, and structures will utilize codes to predict response, as well as sensitivity information. The constraint-providing disciplines of acoustics and airframe dynamics have the analysis task of defining the impact of the design on acoustic energy and fuselage response.

The aerodynamic analysis for rotor performance prediction will include a hover momentum/strip theory code for hover and climb applications (ref. 13). The CAMRAD analysis will be used for forward flight and maneuver performance. In order to assure that the latest developments in inflow analyses are available, some modularity will be provided in the inflow modeling based on recent fidelity assessments (ref. 14).

Rotor dynamics will utilize CAMRAD for forced response calculations. Finite element modeling (ref. 15) and modal analysis (ref. 16) will form the tools for the dynamic tuning before the global analysis predicts the final blade loads, response, and rotor stability.

The structural codes involve a combination of beam analysis and laminate analysis. The beam analysis (e.g., ref. 12) is applied to the blade planform model. The laminate analysis will be applied to one or more cross-section models. The beam model consists of equivalent stiffness and masses from which displacements and forces are computed. The internal blade structure is represented by cross-section models to calculate resultant stresses associated with each beam model segment. The laminate analysis then uses these stresses to determine critical structural margins of safety.

The effectiveness of imposing Phase 1 acoustic constraints will be quantified by using the WOPWOP code (ref. 17), with appropriate loading inputs from CAMRAD. Low frequency loading, thickness, and BVI noise will be generated from this analysis.

Airframe dynamics constraints for Phases 1 and 2 will result from fixed-system frequency predictions and will neglect hub motion. Phase 3 of the effort will involve finite element modeling and impedance tailoring to effect favorable rotor-body coupling in the design process. 


\section{ANALYSIS ASPECTS}

Aerodynamic

Dynamic

Structure

Acoustic

Airframe Dynamics
Hover momentum/strip theory

Global forward flight code Inflow modules

Finite element modeling

Modal code

Global analysis/forced response

Eigen analysis for stability

Beam models

Laminate model

WOPWOP code to verity

acoustic acceptability

Fixed system frequency prediction

Finite element models - NASTRAN 


\section{INTERDISCIPLINARY COUPLINGS}

Phase 1 of the Langley rotorcraft optimization effort will utilize several design variables which have historically been significant drivers of disciplinary phenomena. In addition, other variables are being included to provide other unexplored design opportunities. Figure 16 shows our first attempt to quantify the interactions among the disciplines through the design variables. For example, rotor tip speed has driven past rotor designs based solely on acoustics, performance, or dynamics. This variable also influences blade structural integrity and fixed system response to transmitted loads. This provides the strong interdisciplinary coupling for tip speed shown in figure 16. There are variables, such as blade twist, which can strongly influence some disciplines, such as aerodynamics, while not perturbing others (e.g., structures) and other variables such as hinge offsets which, heretofore, have not greatly influenced conventional rotor design.

It is a significant part of the current design methodology effort to explore not only the obvious strong design variable couplings, but also to address those variables which may provide design synergism for multidisciplinary design goals. This may provide a design key for missions which have not been accomplished with today's rotorcraft.

\begin{tabular}{|c|c|c|c|c|c|}
\hline Variable & Acoustics & $\begin{array}{c}\text { Aerodyn. } \\
\text { (Perf \& Loads) } \\
\end{array}$ & Dynamics & Structures & \begin{tabular}{|l} 
Fuselage \\
Dynamics
\end{tabular} \\
\hline $\begin{array}{l}\text { Airfoil Dist. } \\
\text { Planform } \\
\text { Twist } \\
\text { Tip speed } \\
\text { Blade number } \\
\text { Stiffness } \\
\text { Mass dist. } \\
\text { Hinge offset }\end{array}$ & $\begin{array}{l}\mathbf{S} \\
\mathbf{S} \\
\mathbf{W} \\
\mathbf{S} \\
\mathbf{S} \\
\mathbf{W} \\
\mathbf{W} \\
\mathbf{W}\end{array}$ & $\begin{array}{l}\mathbf{S} \\
\mathbf{S} \\
\mathbf{S} \\
\mathbf{S} \\
\mathbf{W} \\
\mathbf{S} \\
\mathbf{W} \\
\mathbf{W}\end{array}$ & $\begin{array}{l}W \\
S \\
S \\
S \\
S \\
S \\
S \\
S / W\end{array}$ & $\begin{array}{l}W \\
S \\
W \\
S \\
W \\
S \\
S \\
W\end{array}$ & $\begin{array}{l}W \\
\text { S/W } \\
W \\
S \\
S \\
S / W \\
\text { S/W } \\
\text { S/W }\end{array}$ \\
\hline
\end{tabular}

$S=$ Strong interaction

$W=$ Weak interaction

Figure 16 


\section{INTEGRATED AERODYNAMIC/DYNAMIC/STRUCTURAL OPTIMIZATION OF ROTOR BLADES}

Figure 17 is a flow chart which explains how the integrated procedure will function. The current set of design variables (summarized in fig. 11) will be input to design variable preprocessors which will generate input tailored for each analysis. For example, box beam cross-sectional dimensions will be used to compute values of EI and GJ for use in the dynamic analysis. Each disciplinary analysis will be carried out using the preprocessed data along with the necessary input which is the product of other disciplinary analyses. For example, as the flow chart shows, the dynamic response requires airloads from the aerodynamic loads analysis. The appropriate output from each disciplinary analysis is collected in a module which computes the objective function (fig. 9) and constraints (figs. 13 and 14). The next major step is the sensitivity analysis to calculate derivatives of the objective function and constraints with respect to the design variables. At this stage, all the information is available for the optimizer module (based on the program CONMIN (ref. 18)) wherein the values of the design variables are updated. The above steps are repeated until a converged design is obtained. Convergence requires that the objective function is minimized and all constraints are satisfied.

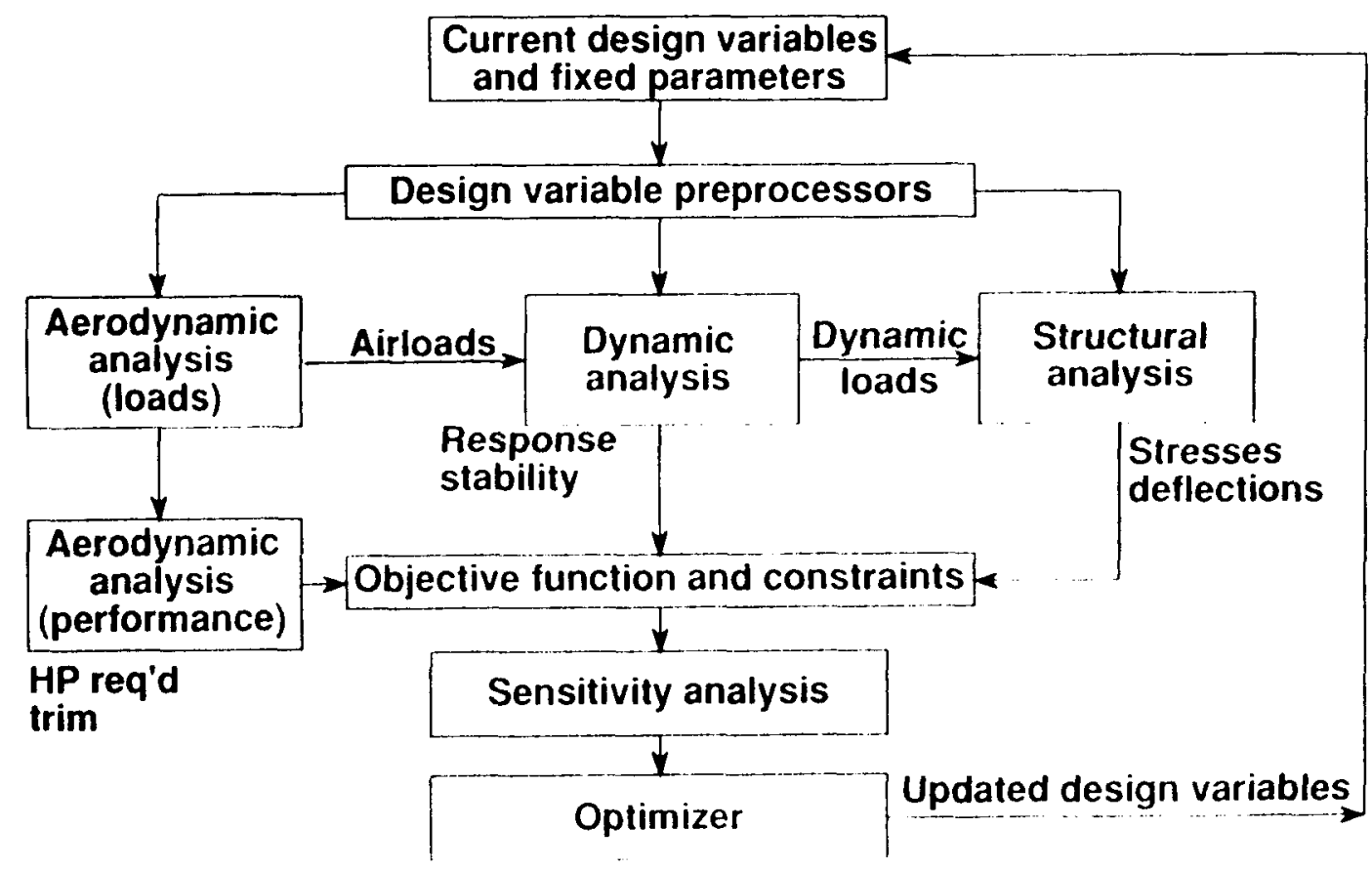

Figure 17 


\section{RESULTS OBTAINED TO DATE}

As indicated in figure 18, progress has been made in the areas of aerodynamic performance optimization, dynamic optimization, optimum placement of tuning masses for vibration reduction, and structural optimization. Selected results from these activities are highlighted in the next portion of the paper.

- Aerodynamic performance optimization

- Dynamic optimization

- Optimum placement of tuning masses

- Structural optimization

Figure 18 


\section{RESULTS - AERODYNAMIC PERFORMANCE OPTIMIZATION}

A Mathematical Programming technique has been developed to minimize the hover horsepower for a helicopter with a specified design gross weight operating at a specified altitude and temperature (fig. 19). A conventional design approach is a two-step iterative method. The first step is design for optimum hover performance by varying taper ratio, point of taper initiation, and twist until the rotor blade configuration with the lowest hover horsepower is obtained. In the second step, this best hover design is modified by changing the root chord to meet forward flight and maneuverability requirements. The Mathematical Programming approach uses the same performance analyses as the conventional approach, but couples a general-purpose optimization program to the analyses. The conventional and Mathematical Programming approaches have been used to define the blade configuration which provides the lowest hover horsepower and satisfies forward flight and maneuverability requirements. The figure also summarizes results for the final design variable values and the main rotor horsepower required for hover from each approach. The Mathematical Programming approach produced a design with more twist, a point of taper initiation further outboard, and a smaller blade root chord than the conventional approach. The Mathematical Programming design required 25 less hover horsepower than the conventional design. Most significantly, the Mathematical Programming approach obtained results more than ten times faster than the conventional approach.

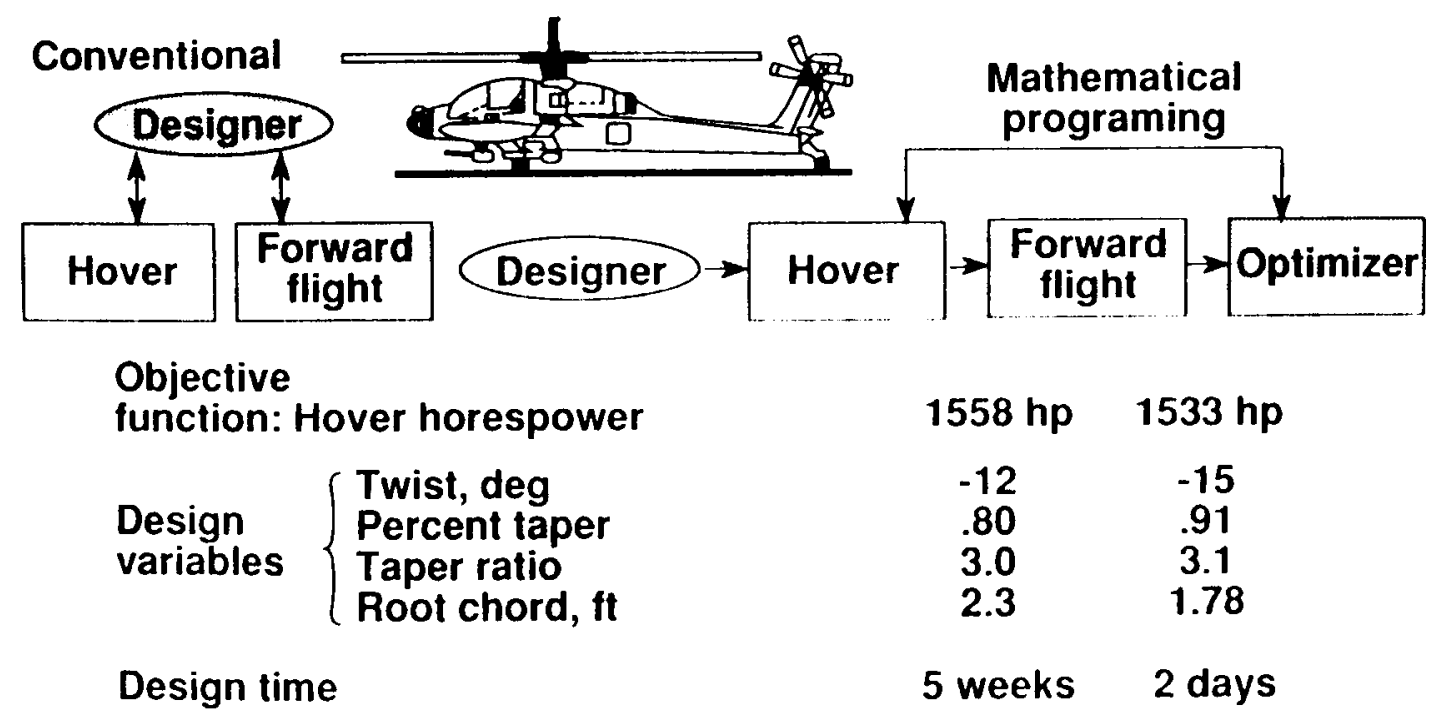

Figure 19 


\title{
RESULTS - DYNAMIC OPTIMIZATION
}

A rotor dynamic optimization problem is summarized in figure 20. Blade mass is the objective function. Upper and lower bound constraints are placed on the first five natural frequencies (elastic modes only) of the blades to separate them from the excitation frequencies. Also, a lower bound constraint is imposed on the blade autorotational inertia. A stress constraint is used to guard against structural failure due to blade centrifugal stress, and side constraints are imposed on the design variables to avoid impractical designs. The design variables are the box beam spar wall thicknesses, the magnitudes of tuning masses, the blade taper ratio, and the box beam height at the blade root. The program CAMRAD and CONMIN are used for the blade modal analysis and the optimization, respectively. A sensitivity analysis calculates analytical derivatives of the objective function, autorotational inertia and stress constraints, along with finite difference derivatives of the frequency constraints.

\author{
Objective function - blade mass $W$ \\ $W=W_{b}+W_{0} \quad W_{b}=$ box beam mass$$
W_{0}=\text { nonstructural mass }
$$ \\ Constraints \\ $\begin{array}{lrl}\text { Frequency: } f_{i 1} \leq f_{i} \leq f_{i_{u}} & f_{i}>\text { first three } \\ \text { Autorotational inertia: } & \text { lead-lag }\end{array}$ \\ $\left(\sum_{j=1}^{N} w_{j} r_{j}^{2}\right) \geq \alpha$ \\ first two flap \\ $\alpha$ : minimuim rotary \\ inertia \\ Stress constraints: $\sigma /$ centrifugal $\leq \sigma a$ \\ Design variables - Box beam cross-sectional dimensions \\ Tuning masses \\ Blade taper ratio
}

Figure 20 


\section{RESULTS - DYNAMIC OPTIMIZATION (CONCLUDED)}

Optimum designs for minimum mass rotor blades have been obtained for both rectangular and tapered blades. The optimum designs are compared with an existing baseline blade denoted the 'reference' blade in figure 21 . The reference blade is based on an actual flight article and is described in more detail in references 5 and 9. The figure also shows the box beam wall thickness distributions for the rectangular blade using 30 design variables $\left(t_{1}, t_{2}, t_{3}\right.$ at ten spanwise locations), and for the tapered blade with 42 design variables (ten lumped masses, and $h_{r}$ and $\lambda_{h}$ are the additional design variables). Blade mass reductions of four to six percent (compared to a baseline or reference blade) have been achieved without violating the imposed constraints. The optimization process tends to shift the wall thickness distribution outboard for both designs due to the presence of the autorotational inertia constraint. The tapered design requires more outboard mass shift, but this is easily accomplished within the stress constraints.

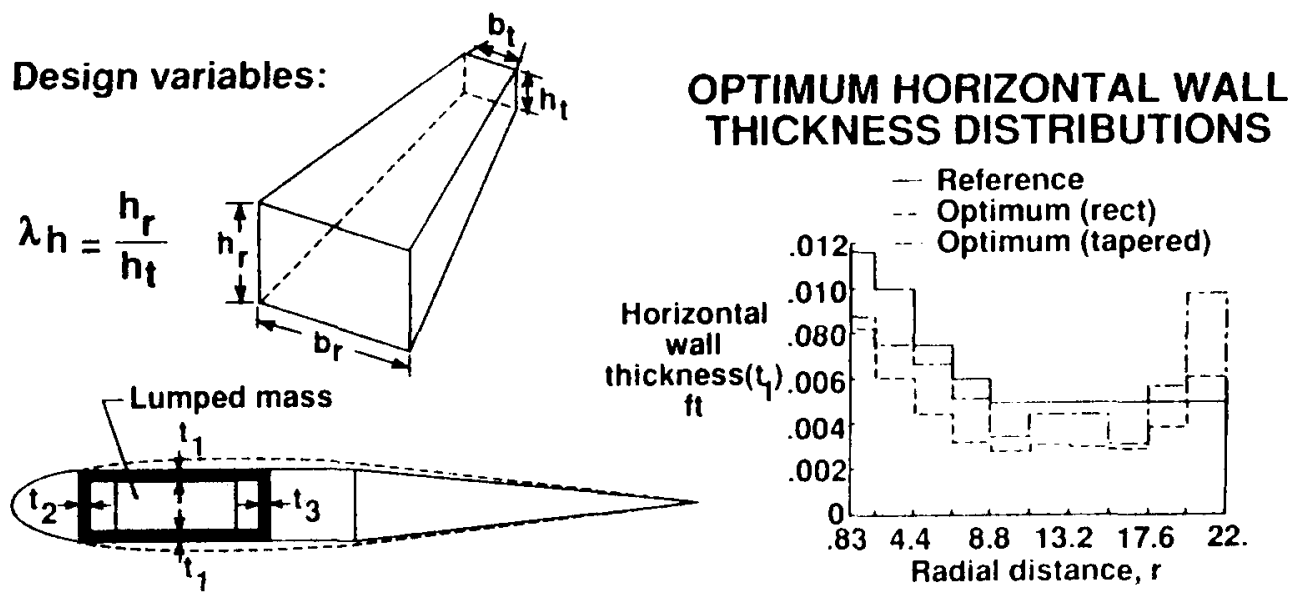

\begin{tabular}{|c|c|c|c|}
\hline \multirow{2}{*}{$\begin{array}{c}\text { Blade weight } \\
\text { (lbs) }\end{array}$} & Reference & \multicolumn{2}{|c|}{ Optimum } \\
\cline { 2 - 4 } $\begin{array}{c}\text { Rectangular } \\
\text { Percent reduction }\end{array}$ & 98.3 & 93.6 & 92.1 \\
& $\cdots$ & 4.7 & 6.2 \\
\hline
\end{tabular}

Figure 21 


\section{RESULTS - OPTIMUM PLACEMENT OF TUNING MASSES}

The design problem (shown in figure 22) is to find the best combination of tuning masses and their locations to minimize blade root vertical shear without a large mass penalty. The objective function is a combination of vertical shear and the sum of the tuning masses. Constraints are placed on the frequencies to avoid resonance. The strategy employed reduces the total shear as a function of time during a revolution of the blade.

The example problem (figure 23) is a beam representation of an articulated rotor blade. The beam is 193 inches long with a hinged end condition and is modeled by ten finite elements of equal length. The model contains both structural mass and lumped (non-structural) masses. Three lumped masses are to be placed along the length of the beam. The strategy was applied to a test case of two modes responding to three harmonics of airload. The figure compares the blade vertical root shear $s(t)$ plotted versus azimuth for the initial and final designs. The peaks on the initial curve have been reduced dramatically. For example, the oscillatory (1/2 p-p) load was reduced from $78 \mathrm{lbs}$ to $0.6 \mathrm{lbs}$ - nearly two orders of magnitude.

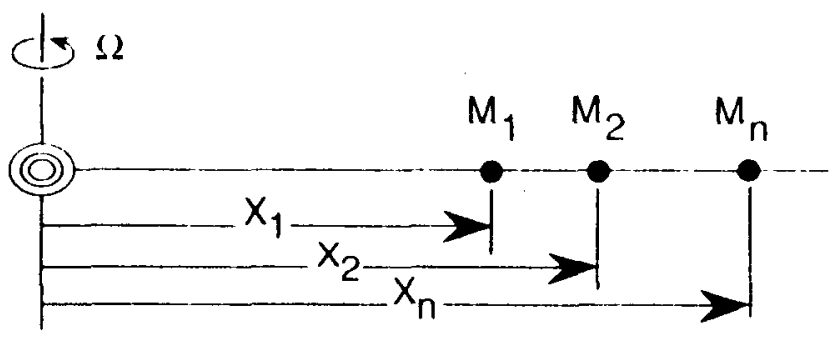

- Design goal - Find optimum combination of masses and their locations to reduce blade root vertical shear

- Method - Formulate optimization procedure

- Use masses and locations as design variables

- Minimize -

- Blade root vertical shear

- Added mass

Figure 22 


\section{RESULTS - OPTIMUM PLACEMENT OF TUNING MASSES (CONCLUDED)}

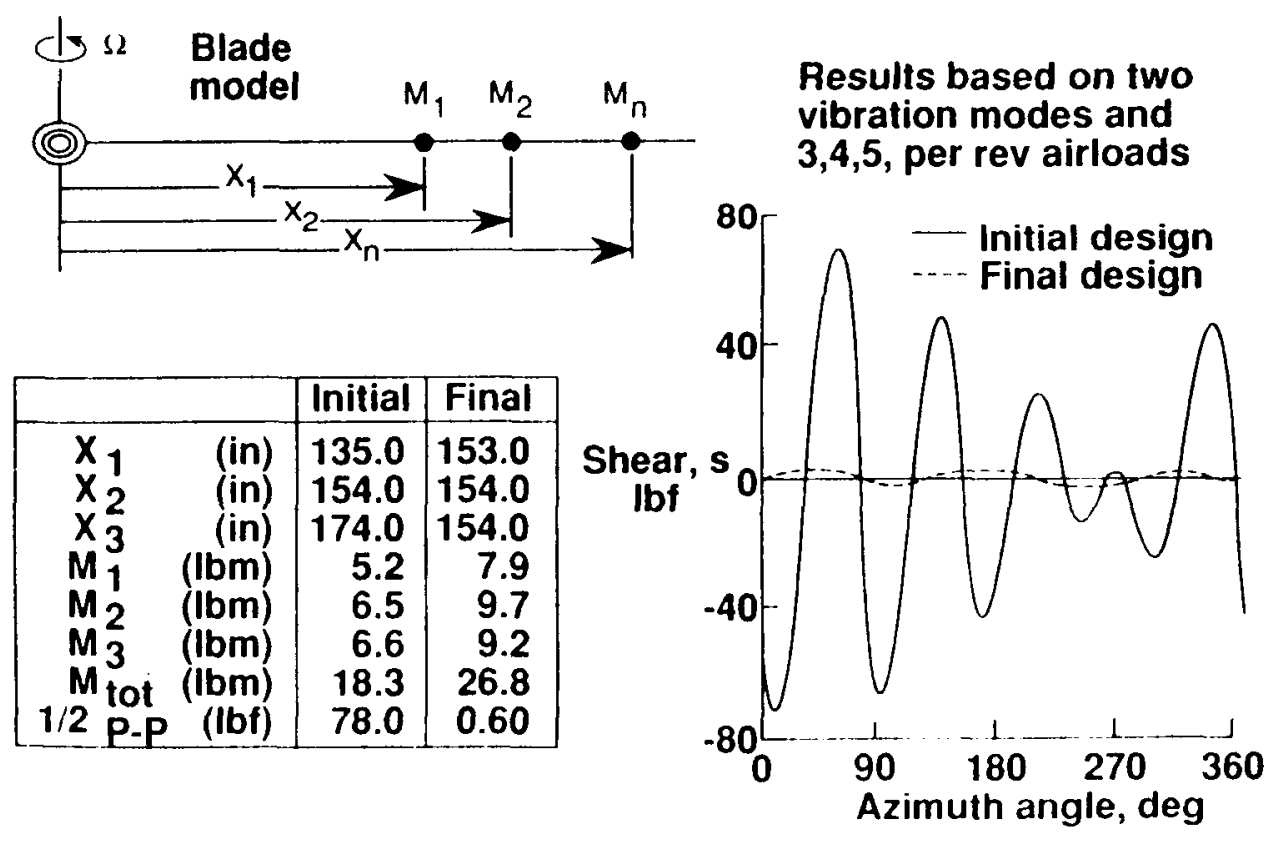

Figure 23 


\section{RESULTS - STRUCTURAL OPTIMIZATION}

A blade structural optimization procedure (fig. 24) applicable to metal and composite blades has been developed in which the objective function is blade mass with constraints on stresses in the spars and in the skin, twist deformation, and autorotational inertia. The design variables are the total spar thickness and for the composite blade the percentage of $\pm 45^{\circ}$ plies (the remaining plies assumed to be at $0^{\circ}$ ). This procedure is described in detail in reference 12 , and additional applications of the methods are also given in reference 12 .

- Objective function: Blade mass

- Constraints:

Stress in skin and spars, twist deformation, autorotational inertia

- Design variables: Spar thicknesses, $\%$ of $\pm 45^{\circ}$ plies

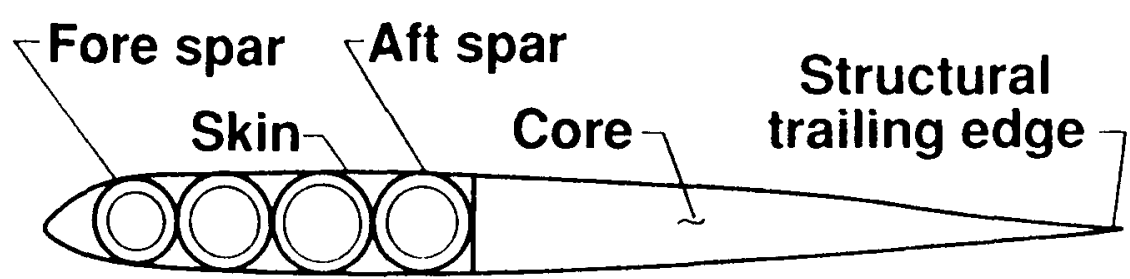

Figure 24 


\section{RESULTS - STRUCTURAL OPTIMIZATION (CONCLUDED)}

Two examples rotor blade design (fig. 25) were generated using the structural design methodology. Both designs use the UH-60A Black Hawk titanium spar blade as a baseline. First, a titanium spar blade design was generated. A maximum twist deformation of 3.1 degrees was selected. The structural constraint requires that the calculated stresses not exceed the allowable material strength which is assessed using the Tsai-Hill failure criterion (ref. 12). The autorotational capability is satisfied by requiring the mass moment of inertia to be at least 19000 in-lbs-s ${ }^{2}$ per blade.

As shown in figure 25 , the minimum metal spar thickness which satisfies all of the constraints is .130 inches and corresponds to a blade weight of 207 pounds. The actual UH-60A titanium spar is .135 inches thick and weighs 210 pounds. The new titanium spar design is only three pounds different from the actual UH-60A blade, demonstrating that the mechanics of the design methodology can produce blade designs similar to conventional design processes for the same design allowances and material. A second design was developed using a single T300/5208 graphite/epoxy D-spar. The composite design also satisfied the required constraints and the minimum weight design had a .105 inch thick spar with 20 percent of the plies oriented at \pm 45 degrees. The composite blade weighed 163 pounds which represents a 21.5 percent reduction over the actual UH-60A blade.

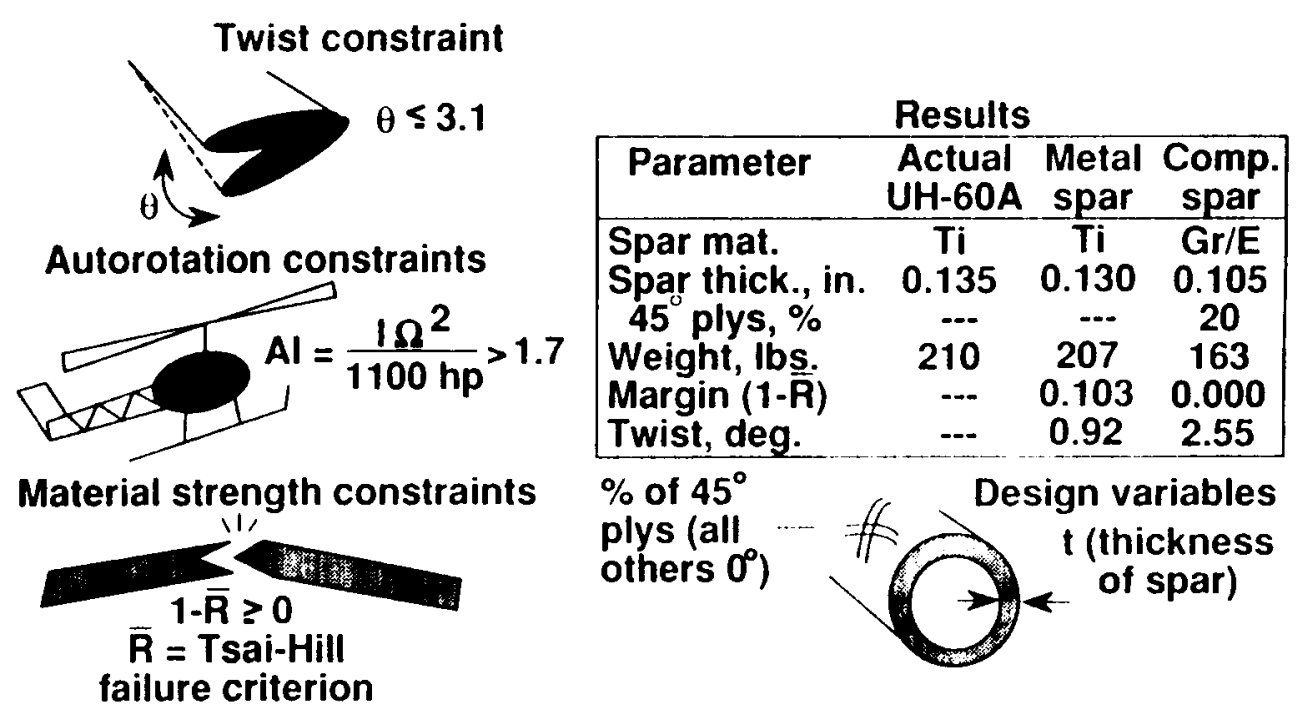

Figure 25 


\section{VALIDATION OF PROCEDURES}

The process of validating the optimization methodology (fig. 26) involves substantially more than evaluating the success of the final design. Specifically, the analyses used in optimizing the rotor during the Phase 1 effort will be examined for predictive fidelity and design technique validation. The usefulness of the basic tools involves not only accuracy of analysis, but also a reliable parametric sensitivity capability. Several opportunities are currently available to assess the fidelity of the analyses. For example, rotor performance, dynamics, and acoustics predictions need accurate inflow distributions for various flight conditions. Recent experimental efforts (e.g., ref. 19) and code validations (ref. 14) are helping to provide confidence in the available inflow models. Rotor geometric design variable sensitivity (e.g., effect of taper on performance) which was reasonably well-known for past rotor designs, is being re-examined in light of recent correlation anomalies for high-speed flight. Acoustic source mechanisms and modeling validity are also being examined (ref. 20), especially for parametric sensitivity of the acoustic energy to rotor state. Structural coupling mechanics are being exploited in new rotor designs to assess the structural tailoring benefits while satisfying structural integrity requirements (ref. 22).

Proof of the fidelity of design techniques is crucial to the overall design optimization effort. For example, aerodynamics and dynamics interact so strongly in rotor design that basic aeroelastic tailoring efforts must be validated. Such a validation effort is being undertaken at Langley, as well as other research centers (ref. 22). Also, since rotor speed is a strong driver for aeroelastic response, a program to assess variable RPM designs is underway at Langley. The object of this effort is to define the benefits and limitations of an aerodynamically and dynamically designed multi-speed rotor. In addition to design techniques, which capitalize on the strong effects of certain design variables, small variances in other blade characteristics may impede the practical operation of even conventional designs. Hence, the ability to accurately predict even these secondary phenomena is important for the design effort. For example, track-and-balance sensitivity experiments and studies are being undertaken which can lead to a practical design capability to eliminate blade-to-blade variability effects. 


\section{VALIDATION OF PROCEDURES}

- Basic predictive tools

- Rotor inflow fidelity

- Acoustic source mechanisims

- BVI

- Loading

- Thickness

- Composite structional couplings

- Parametric taper initiation studies

- Design technique validations

- Blade dynamic tailoring

- Variable RPM designs

- Blade-to-blade variability effects

Figure 26 


\section{OVERALL DESIGN VALIDATION}

For the overall Phase 1 validation effort (fig. 27), the Langley team has chosen a rotor task which requires maneuverability, speed, and efficiency. Specifically, the rotor mission must be accomplished with minimum power and vibration while satisfying predefined acoustic, stability, and fuselage dynamics requirements.

The assessment of the Phase 1 design methods will involve model rotor hover and wind tunnel tests. The models (a baseline and an advanced design) will be aerodynamically and dynamically scaled. Provisions for varying key design parameters are necessary to complete the validation process. In other words, the tests need to quantify not only a minima, but the gradients around it. The testing possibilities include a series of $1 / 5$-scale model rotors, mounted on a variable drive system and tested in hover and simulated forward flight in a tunnel which can eliminate many testing "excuses" such as inappropriate Reynolds, Mach, and Froude Numbers. The Langley TDT is the candidate facility for the major segments of the validation process.

\section{- Definition of mission profile at gw/altitude/power - Maneuverability \\ - Speed \\ - Efficiency \\ - Minimize objective function while satisfying constraints \\ - Wind tunnel model rotors \\ - Baseline \\ - Advanced design with some parametric variability \\ - Aerodynamicaly and dynamically scaled}

Figure 27 


\section{CONCLUDING REMARKS}

This paper has described a joint NASA/Army initiative at the Langley Research Center to develop optimization procedures aimed at improving the rotor blade design process by integrating appropriate disciplines and accounting for important interactions among the disciplines. The activity is being guided by a Steering Committee made up of key NASA and Army researchers and managers. The committee, which has been named IRASC (Integrated Rotorcraft Analysis Steering Committee), has defined two principal foci for the activity: a "white paper" which sets forth the goals and plans of the effort; and a rotor design project which will validate the basic constituents, as well as the overall design methodology for multidisciplinary optimization.

This paper has described the optimization formulation in terms of the objective function, design variables, and constraints. Additionally, some of the analysis aspects were discussed and an initial attempt at defining the interdisciplinary couplings was described. At this writing, some significant progress has been made - principally in the areas of single discipline optimization. Results were given in the paper which represent accomplishments in rotor aerodynamic performance optimization for minimum hover horsepower, rotor dynamic optimization for vibration reduction, and rotor structural optimization for minimum weight.

- Defined objectives and procedures for integrated rotorcraft design

- Formalized Army/NASA team Researchers and Managers

- Goals - Two foci

- White paper to be critiqued by industry

- Rotor design to validate procedures and tools

- Disciplinary optimization and coupling methodologies already yielding useful results

- Rotor aerodynamic performance

- Rotor dynamics

- Rotor structure

Figure 28 


\section{REFERENCES}

1. Ashley, H.: On Making Things the Best - Aeronautical Use of Optimization. Journal of Aircraft, Vol. 19, No. 1, 1982, pp. 5-28.

2. Sobieszczanski-Sobieski, J.: Structural Optimization Challenges and Opportunities. Presented at International Conference on Modern Vehicle Design Analysis, London, England, June 1983.

3. Miura, H.: Application of Numerical Optimization Methods to Helicopter Design Problems: A Survey. NASA TM-86010, October 1984.

4. Bennett, R. L.: Application of Optimization Methods to Rotor Design Problems. Vertica, Vol. 7, No. 3, 1983, pp. 201-208.

5. Peters, D. A.; Rossow, M. P.; Korn, A.; and Ko, T.: Design of Helicopter Rotor Blades for Optimum Dynamic Characteristics. Computers and Mathematics with Applications, Vol. 12A, No. 1, 1986, pp. 85-109.

6. Friedmann, P.: Application of Modern Structural Optimization to Vibration Reduction in Rotorcraft. Vertica, Vol. 9, No. 4, 1986, pp. 363-376.

7. Friedmann, P.; and Shanthakumaran, P.: Optimum Design of Rotor Blades for Vibration Reduction in Forward Flight. Journal of American Helicopter Society, October 1984, pp. 70-80.

8. Davis, M. W.: Optimization of Helicopter Rotor Blade Design for Minimum Vibration. NASA CP-2327, Part 2, September 1984, pp. 609-625.

9. Chattopadhyay, Aditi; and Walsh, Joanne L.: Minimum Weight Design of Rotorcraft Blades with Multiple Frequency and Stress Constraints. Proceedings of the AIAA/ASME/ASCE/AHS 29th Structures, Structural Dynamics and Materials Conference, Williamsburg, VA, April 18-20, 1988. AIAA Paper No. 88-2337-CP. Also available as NASA TM-100569, March 1988. 
10. Walsh, J. L.; Bingham, G. J.; and Riley, M. F.: Optimization Methods Applied to the Aerodynamic Design of Helicopter Rotor Blades. Journal of American Helicopter Society, October 1987, pp. 39-44.

11. Kumar, S.; and Bassett, D.: Rotor Performance Optimization for Future Light Helicopters. Proceedings of the 43rd Annual AHS Forum, St. Louis, MO, May 18-20, 1987.

12. Nixon, M. W.: Preliminary Structural Design of Composite Main Rotor Blades for Minimum Weight. NASA TP-2730, July 1987.

13. Gessow, Alfred; and Myers, Garry C., Jr.: Aerodynamics of the Helicopter. Frederick Unger Publishing Company, NY, 1952.

14. Berry, J. D.; Hoad, D. R.; Elliott, J. W.; and Althoff, S. L.: Helicopter Rotor Induced Velocities, Theory and Experiment. Proceedings of the AHS Specialists Meeting on Aerodynamics Acoustics, Fort Worth, TX, February 1987.

15. Whetstone, W. D.: Engineering Analysis Language Reference Manual EISI-EAL System Lend, 2091. Engineering Information Systems, July 1983.

16. Lang, K. W.; and Nemat-Nasser, S.: An Approach for Estimating Vibration Characteristics of Non-uniform Rotor Blades. AIAA Journal, Vol. 17, No. 9, September 1979.

17. Brentner, K. S.: Prediction of Helicopter Rotor Discrete Frequency Noise - A Computer Program Incorporating Realistic Blade Motions and Advanced Acoustic Formulation. NASA TM-87721, October 1986.

18. Vanderplaats, G. N.: CONMIN - A Fortran Program for Constrained Function Minimization. User's Manual. NASA TMX-62282, August 1973.

19. Elliott, J. W.; Althoff, S. L.; and Sailey, R. H.: Inflow Measurement Made with a Laser Velocimeter on a Helicopter Model in Forward Flight. NASA TM-10054l, April 1988.

20. Cardonna, F. X.; Lantenschlager, J. L.; and Silva, M. J.: An Experimental Study of RotorVortex Interactions. AIAA Paper No. 88-0045. Presented at AIAA 26th Aerospace Sciences Meeting, Reno, Nevada, January 1988. 
21. Lake, R. C.; and Nixon, M. W.: A Preliminary Investigation of Finite-Element Modeling in Analysis for Composite Rotor Blades. Proceedings of the Second International Conference on Rotorcraft Basic Research, College Park, Maryland, February 1988.

22. Weller, William H.; and Davis, Mark W.: Experimental Verification of Helicopter Blade Designs Optimized for Minimum Vibration. Proceedings of the 44th Annual Forum of the American Helicopter Society, Washington, DC, June 1988. 


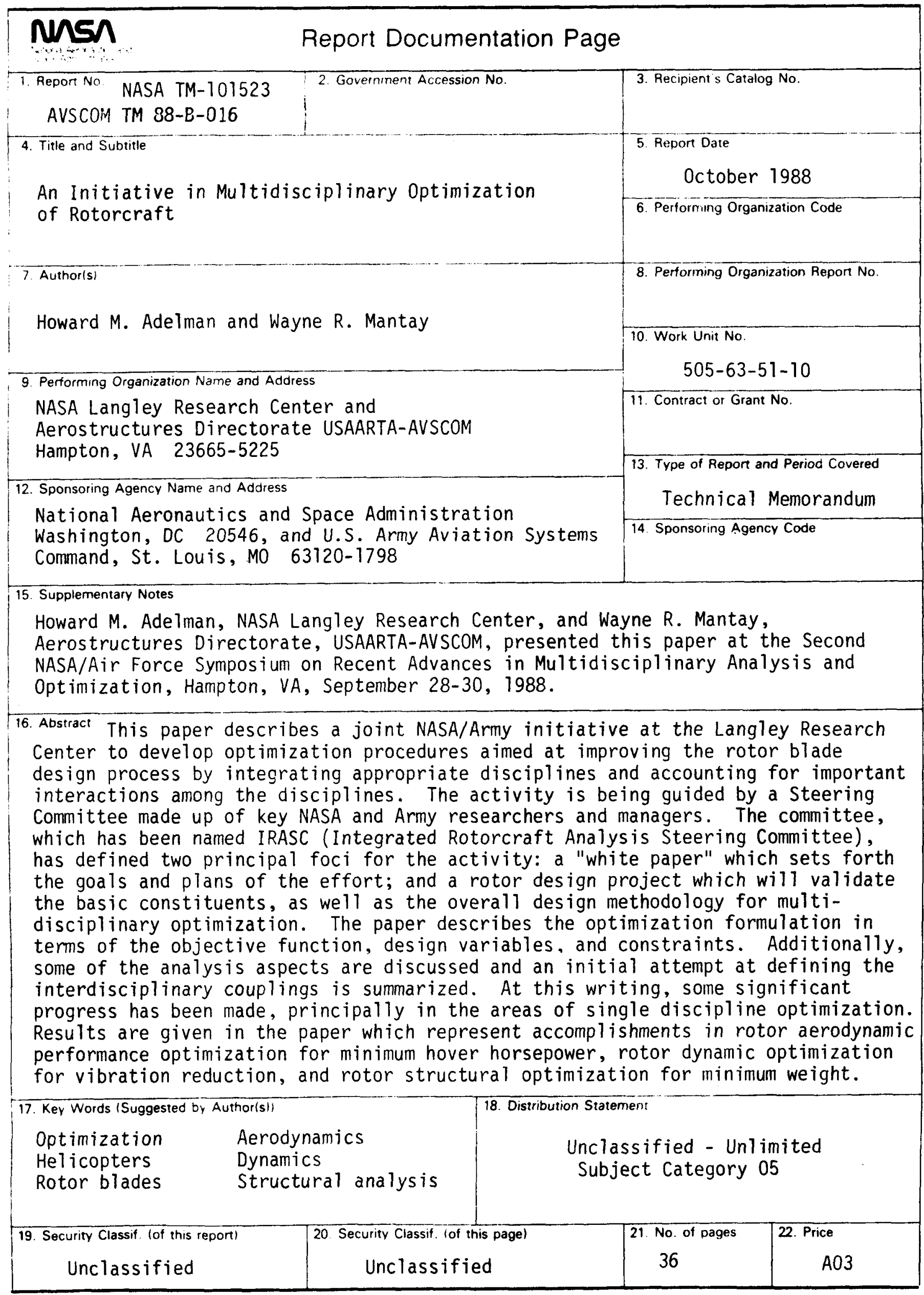

